\title{
Interaction of infectious bursal disease virus with the immune system of poultry
}

\author{
Z.U. REHMAN ${ }^{1,2}$, C. MENG ${ }^{1}$, S. UMAR ${ }^{3,4}$, M. MUNIR ${ }^{5}$ and C. DING ${ }^{1 *}$ \\ ${ }^{1}$ Shanghai Veterinary Research Institute (SHVRI), Chinese Academy of \\ Agricultural Sciences (CAAS), 200241, China; ${ }^{2}$ Department of Poultry Science, \\ Faculty of Veterinary and Animal Sciences, PMAS Arid Agriculture University, \\ Rawalpindi, Pakistan; ${ }^{3}$ Department of Pathobiology, Faculty of Veterinary and \\ Animal Sciences, PMAS Arid Agriculture University, Rawalpindi, Pakistan; \\ ${ }^{4}$ National Veterinary School, Toulouse, France; ${ }^{5}$ Avian Innate Immunity and Host \\ Genetic Diversity, Avian Viral Diseases Programme, The Pirbright Institute, Surrey, \\ GU24 0NF, United Kingdom \\ *Corresponding author: shoveldeen@shvri.ac.cn
}

Immune dysfunction can be either at the humoral or cellular levels and is mediated by a myriad of factors including virus-induced immunosuppression. Infectious bursal disease virus (IBDV) affects domesticated poultry and causing health problems mainly due to prolonged immunosuppression. Destruction of the immunoglobulin-producing cells is the principal cause of IBDV-induced immunosuppression, which leads to significant impairment of the primary antibody responses. Due to these effects, IBDV infection not only increases the susceptibility of poultry to other viral infections but predisposes the host to several other bacteria of variable pathologies. The IBDV-induced immunesuppression is well-known phenomenon, however, recently there have been significant advancements in understanding the molecular mechanisms of this immune-suppression. This review discuss current updates regarding the immunotoxic and immunosuppressive nature of IBDV in the poultry and highlights areas requiring future research attentions that may help to establish foundations for effective and improved vaccines against IBDV.

Keywords: infectious bursal disease virus; immunity; immune cells; immunosuppression; poultry

\section{Introduction}

The world's poultry industry is growing at a reasonable pace, but those involved have to minimise the occurrence of diseases and immunosuppression to enhance the profit in this competitive industry. One of the most treacherous immunosuppressive diseases in poultry is infectious bursal disease (IBD), which threatens the poultry industry throughout the

(C) World's Poultry Science Association 2016

World's Poultry Science Journal, Vol. 72, December 2016

Received for publication June 12, 2016

Accepted for publication August 28, 2016 
world (Mahgoub et al., 2012; Qi et al., 2014). IBD virus (IBDV), a highly immunosuppressive virus, characteristically replicates in the lymphoid organs and directly suppresses the functionality of the immune system (Zhai et al., 2014).

IBDV is a double-stranded RNA virus, belonging to the genus Avibirnavirus within the family Birnaviridae (Müller et al., 1979; Mahgoub et al., 2012; Ndashe et al., 2016). Double-stranded RNA of the IBDV genome is made up of two segments A and B (Figure 1). Segment A has two partially overlapping open reading frames (ORFs), known as major and minor. Major ORF encodes a polyprotein, which via autoproteolysis produce viral proteins VP2, VP4 and VP3 and the minor ORF encodes for VP5 (a non-structural protein). VP1 of the IBDV is encoded by the RNA-dependent RNA polymerase, an ORF present on the segment B of the IBDV (Ndashe et al., 2016; Mahgoub et al., 2012). IBDV structure is a non-enveloped, single-shelled icosahedral symmetry capsid of about $70 \mathrm{~nm}$ in diameter, composed of 260 trimers of VP2 that form spikes projecting radially from the capsid. The peptides derived from pre-VP2 C-terminal cleavages remain associated within virion. VP3 forms a ribonucleoprotein complex with the genomic RNA. Minor amounts of VP1 are incorporated in the virion. Segmented linear dsRNA genome: 2 segments (A, B) encode for 5-6 proteins. VP1 is found in a free form and covalently attached at the 5' genomic RNA end (VPg). Segments size is about 2.3-3 $\mathrm{kb}$ and genome total size is about $6 \mathrm{~kb}$. Genomic segment A encodes for a structural polyprotein which is matured in cis by VP4. It also encodes an alternative ORF translated possibly by leaky scanning (VP5).Genomic segment B encodes for VP1 (http://viralzone.expasy.org/viralzone/all_by_species/572.html).
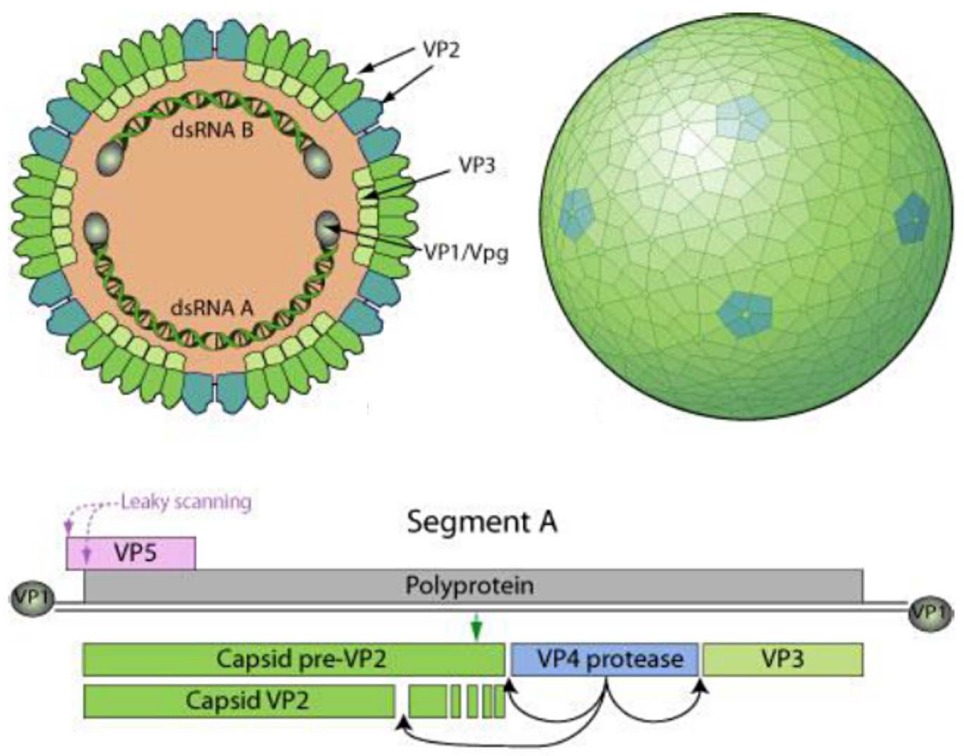

Segment B

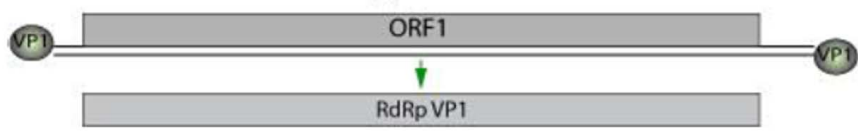

Figure 1 Structure and genetic coding for IBD virus. 
When IBDV invade the body, the innate immune system is activated first and participates in the initial attack against the pathogens. Among the cells involved in innate immunity, dendritic cells (DCs) act as antigen-presenting cells and migrate from the infected tissue to the regional lymph nodes where they present the antigens to $\mathrm{T}$ cells (Akira, 2011). Subsequently, the adaptive immune system is activated and antibody production and killer $\mathrm{T}$ cells are induced. The resulting antibodies and killer $\mathrm{T}$ cells specifically attack the pathogens (Figure 2).

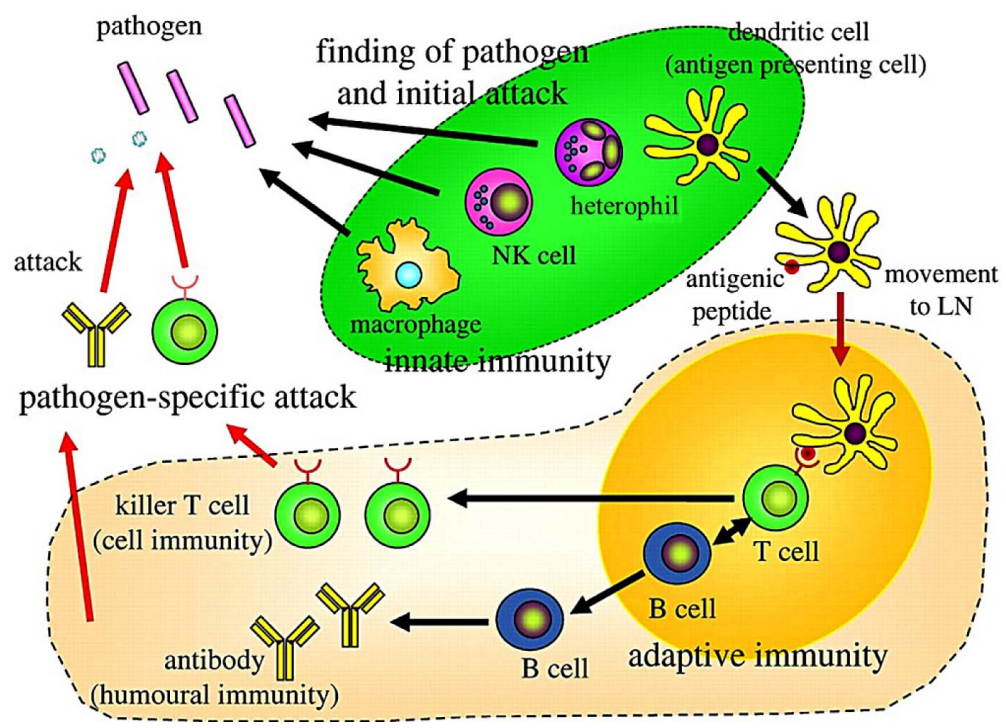

Figure 2 Interactions of innate and adaptive immunity when pathogens invade the body (Adopted from Akira, 2011).

Immunosuppression decreases weight gain and production and increases carcass condemnation rates at processing plants. Moreover, immune dysfunction also increases the rate of mortality and morbidity mainly due to secondary viral and bacterial infections (Fussell, 1998). There are two serotypes reported so far for IBDV; IBDV 1 and IBDV 2. Clinical disease is only caused by the serotype 1 in chickens, but serotype 2 can infect turkeys, chicken, duck but does not cause clinical symptoms. On the basis of the virulence, serotype 1 is classified into classical virulent, antigenic variant, very virulent and attenuated strains (Table 1). 
Immune interactions of infectious bursal disease virus: Z.U. Rehman et al.

Table 1 Viral proteins and their roles in pathogenesis of IBDV.

\begin{tabular}{ll}
\hline Virus protein & Role in pathogenesis \\
\hline VP1 (RNA dependent RNA polymerase) & Encapsidation of viral particle \\
\hline VP2 (external capsid protein) & $\begin{array}{l}\text { Contain antigenic regions responsible for : } \\
\text { - Serotype specific } \\
\text { Elicit neutralising antibodies }\end{array}$ \\
\hline VP3 (internal capsid protein) & Morphogenesis of virus \\
\hline VP4 (minor non-structural protein) & $\begin{array}{l}\text { Viral protease (maturation of VP2 trimming peptides } \\
\text { during virus assembly) }\end{array}$ \\
\hline VP5 (regulatory protein) & B-lymphocyte lysis \\
\hline
\end{tabular}

Chickens are highly susceptible to IBDV between ages of three and six weeks posthatching (Aricibasi et al., 2010). Mechanisms of pathogenic and immunosuppressive aspects of IBDV are still not well known (Escaffre et al., 2013; Lee et al., 2014; Ouyang et al., 2015), however, it has been shown that IBDV causes the disruption of innate immune responses, macrophages (MФ), T cells, DCs, and also the massive destruction of B cells (Mahgoub et al., 2012). A suppressed immune system is the frontrunner for suboptimal vaccine responses, thus leading to increased susceptibility to other diseases (Schat and Skinner, 2014; Prandini et al., 2016). This review discusses current research regarding the immunotoxic and immunosuppressive nature of IBDV in the poultry and highlights areas requiring future research attentions that may help to establish foundations for effective and improved vaccines against IBDV.

\section{Interaction of innate immune responses with IBDV}

Innate immunity is the primary barrier against pathogens, and intestinal mucosa is the first barrier that prevents the invasion of the IBDV. Intestinal mucosa may have direct role in regulation of the adaptive immune responses (Wang et al., 2009b). IBDV uses its one of four structural proteins (pep46) to disturb the cell membrane and enter the target cells. This structural protein deforms the membrane and makes the pores open. The virus enters the target cells in a multiple step process; first of all it recognises the target cell, endocytoses in the presence of calcium and releases pep46. After this, membrane destabilisation starts and pores are formed $10 \mathrm{~nm}$ in size that can be seen through electron microscope. As the size of the virus is $70 \mathrm{~nm}$, so it cannot enter into the cytoplasm, indicating that virus uses these pores only for the transfer of small molecules that initiate genetic transcription and subsequently translocation (Galloux et al., 2007).

Innate immune responses depend on pattern-recognition receptors (PRR), such as tolllike receptors (TLR), retinoic acid-induced gene I (RIG-I)-like receptors (RLR), and nucleotide-binding oligomerisation-domain-like receptors (NLR) to identify the pathogen-associated molecular patterns (PAMP), such as dsRNA, lipopolysaccharide (LPS) and flagella. TLR3 and TLR7 are only involved in viral infection in chickens. TLR3, TLR4 and TRIF is upregulated in IBDV infection in chickens (Rauf et al., 2011a; Guo et al., 2012; Lee et al., 2015a) and chick embryo fibroblasts cells (Wong et al., 
2007). In IBDV infections, expression of TLR2B, TLR4, TLR7 and MyD88 was down regulated (Rauf et al., 2011a; Guo et al., 2012) in the bursa of Fabricius (BF). Down regulation of the TLR2B indicates decreased immune responses (Guo et al., 2012). IBDV also utilises some cellular proteins and uses them for replication and to protect itself from the innate antiviral responses, for example VP3 of the IBDV use the ribosomal protein L4 (RPL4) for the replication (Chen et al., 2016). IBDV protein (VP3) has a high affinity with the chicken melanoma differentiation-associated gene 5 (MDA5), which blocks the signalling pathway to IBDV genomic dsRNA. As a result MDA5 fails to recognise the viral RNA thus prohibiting the antiviral immune response (Ye et al., 2014).

\section{CYTOKINES AND CHEMOKINES}

Cytokines are essential for the activation, differentiation and control of the host immune system. Variation in the expression of the cytokines had been noted in IBDV infection depending on the cells, virus type, age, and different tissues (He et al., 2011; Li et al., 2013a; Lee et al., 2015b; Yasmin et al., 2015). IBDV infection in chicken promotes the expression of the pro-inflammatory cytokines and chemokines, Th1 cytokines, iNOS and MHC class I in HD11 cells in vitro (Rasoli et al., 2015) and upregulate chicken IL-12 and IL-18 in HD11 cells infected with IBDV (Khatri et al., 2005; Lee et al., 2015b). IBDV also upregulates the IL-6, IL-8 and interferons (IFNs) expression in the BF (Carballeda et al., 2014) and IL-8 (Rauf et al., 2011a). Temporary up regulation of IFN- $\gamma$, IL-2, IL- 6 and down regulation of the cytokine IL- $1 \beta$ and type IIFNs were noted in IBDV infection (Rautenschlein et al., 2007; Eldaghayes et al., 2006).

There are three main type of the IFNs which are IFNs type I (IFN-I; IFN $\alpha$, IFN $\beta$ ), Type II (IFN-II; IFN- $\gamma$ ) and Type III (IFN-III; IFN $\lambda$ ). Production of IFN-I is inhibited in IBDV infection in chickens (Eldaghayes et al., 2006) and is not induced in IBDV infected cells either in vivo or in vitro (Ye et al., 2014) although dsRNA induces IFN $\beta$ expression. IBDV infection in HD11 cells induced significantly upregulated expression levels in chicken, IFN- $\beta$ (693-fold) (Lee et al., 2015b) also in BF (Rauf et al., 2011a) and IFN- $\gamma$ in unvaccinated chickens (Lee et al., 2015a). IFN antiviral signal transduction pathway is controlled by the interferon regulatory factor 2 (IRF2). IBDV infection seriously obstructs the production of the IFNs (Ye et al., 2014) by inhibiting the expression of the IRF2 gene by the gga-miR-9, hence promoting the IBDV replication (Ouyang et al., 2015). However, there are some contradictory studies that indicate IRF-1 is upregulated in the IBDV challenged birds after three days post challenge (Lee et al., 2015a). These contradictory results may be due to age, pathogenicity of the virus, days post infection (DPI) when measuring levels and examination of either production or dsRNA expression levels. IFN-I production is not enhanced in cells in vitro or in vivo but the genomic dsRNA induces the IFN- $\beta$ expressions which are triggered by blocking the MDA5 dependent signalling pathway (Ye et al., 2014), and IBDV is unable to inhibit this expression if these are activated (Ye et al., 2014). Another possible pathway is the use of VP4 for inhibition of the IFN-I via communication with the glucocorticoidinduced leucine zipper ( $\mathrm{Li}$ et al., 2013b). So, it is clear that viral proteins affect the antiviral immune responses in IBDV infection by triggering different pathways.

\section{DENDRITIC CELLS}

Dendritic cells (DCs) work like sentinels within the immune system (Levitz and Golenbock, 2012) and present in all parts of the chicken's body, including lymphoid, non-lymphoid, interstitial tissues, skin epidermis, mucosal surfaces and peripheral blood (Liu, 2001). DCs are a vital protagonist in the initiation of the primary immune responses by increasing proliferation of naïve $\mathrm{T}$ cells, differentiation to memory cells (Yasmin et al., 2015) and can direct the T cell response (Juul-Madsen et al., 2014). They recognise 
pathogens by TLRs and cytoplasmic nucleotide-binding oligomerisation domain-like receptors for the initiation of the innate immune response (Mogensen, 2009). Recently, Yasmin et al. (2015) characterised bone marrow derived DCs (chBM-DCs) in chicken inoculated with LPS, inactivated vvIBDV and live vvIBDV. Interestingly, it was reported that vvIBDV infected BM-DC showed significantly higher numbers of apoptotic cells, increased expression of VP3 and VP4. Expression of IL-1 $\beta$, IL-18 and CCR7 was upregulated by the LPS whereas live vvIBDV treatment significantly enhanced the expression of Th1-like cytokines, IFN- $\gamma$ and IL-12 $\alpha$ and TLR3. On the other hand, inactivated vvIBDV-treated BM-DC was unable to increase the expression of the IFN- $\gamma$, IL-12 $\alpha$ and TLR3 (Yasmin et al., 2015).

In another study by Liang et al. (2015) compared the effect of LPS, inactivated IBDV and IBDV on activation and maturation of chBM-DCs. These cells displayed the typical morphology of DCs after LPS or inactivated IBDV or IBDV inoculation. Significantly upregulated expression of chBM-DCs surface CD40 and CD86 molecules, and ability to induce T-cell proliferative response was found in LPS or virus stimulated chBM-DCs than non-stimulated. But, this stimulation was higher for inactive IBDV than live IBDV. In conclusion, IBDV replicate in DCs, alter the expression of immunity gene and trigger the development of specific immune response or memory.

\section{NATURAL KILLER CELLS}

Natural killer (NK) cells are normally present in the dormitory phase in circulation but they start infiltration in the infected tissue by the activation of cytokines (Glas et al., 2000). Their major function is to recognise and kill virally-infected and neoplastic cells. When the ligand of the NK cells interact with the cell-surface receptors, they produce several cytokines like IFN- $\gamma$, which have an immunoregulatory role (Mandal and Viswanathan, 2015).

Studies related to the role of natural killer cells in IBD are limited. Sharma and Lee (1983) have studied the effect of IBDV on two genetic lines of chicken and found that cell cytotoxicity and mitogenic response of the NK cells were not affected by IBDV whereas, Kumar et al. (1998) found functional impairment of the NK cells in IBD cases. Interestingly, IBDV did not constantly boost NK cell levels in chickens, as Rauf et al. (2011b) found a down regulation of the natural killer cell lysin by IBDV.

\section{MACROPHAGES}

Macrophages $(\mathrm{M} \Phi)$ are key cells of the innate immune system and are well equipped to destroy invading pathogens (Khatri and Sharma, 2008; de Geus and Vervelde, 2013; Scanes, 2015). МФ play an important role in presenting the antigens to T cells and serve as a bridge between the cellular and humoral immune response. Some earlier reports indicated that MФ may be susceptible to the IBDV infection (Inoue et al., 1992; Khatri et al., 2005). It has been proposed in many studies that $М \Phi$ are the main cells that transfer the IBDV from the gut to the peripheral tissue (Kim et al., 1998; Lam, 1998; van den Berg et al., 2000; Palmquist et al., 2006; Khatri and Sharma, 2006).

IBDV increase the expression of proinflammatory cytokines IL-1, IL-6, IL-18 and inducible nitric oxide synthase iNOS in the BF (Khatri et al., 2005; Liu et al., 2010) and spleen (Palmquist et al., 2006), and significantly higher levels of nitric oxide in the splenocytes (Kim et al., 1998) and DH11 cells (Rasoli et al., 2015). Moreover, IBDV upregulate IFN- $\beta$ stimulated genes, including those encoding oligoadenylate synthetase (OAS), dsRNA-dependent protein kinase (PKR), myxovirus resistance (Wong et al., 2007; Lee et al., 2015b) cyclooxygenase-2 (COX-2), chemokine (IL-8) (Khatri and Sharma, 2006) and antigen-presenting molecules (Li et al., 2007; Lee et al., 2015b).

IBDV infection enhances the expression of MDA5 (Lee et al., 2015b) and upregulates 
the pro-inflammatory cytokines IL-1 $\beta$, pro-inflammatory chemokines CCL4, CXCLi1 and CXCLi2, and Th1 cytokines IL-12 $\alpha$ and IL-18, and downregulates IL-10 in HD11 cells. This overexpression of pro-inflammatory cytokines and iNOS mRNA demonstrates that IBDV can affect the cellular immune responses, especially MФ. The detailed mechanism of upregulation of the cytokines and INOS in IBDV infections is unknown, but the inhibition of nuclear factor (NF)-KB and $\mathrm{p} 38$ mitogen-activated protein kinases (MAPK) inhibitor lessens the virus-induced iNOS, COX-2, IL-8 and NO production. This means that IBDV use the NF-kB and p38 MAPK to increase the activation of the MФ (Khatri and Sharma, 2006). This upregulation of the cytokines and decrease in the $\mathrm{M} \Phi$ number (Palmquist et al., 2006) may leads to a decrease in number of the resident $\mathrm{M} \Phi$. After upregulation in cytokines and $\mathrm{M} \Phi$ activation, recovery process from the disease is delayed, resulting in cellular immunosuppression depending on the breed, virus dose/strain, and age of the bird (Rauw et al., 2007).

It is possible that macrophage cell line adapted IBD enhanced the antigen presenting ability of $M \Phi$ and improved the activation of the T cells (Khatri and Sharma, 2008). IBDV induce the cytopathic effects and replicate in the primary stem cells, making them highly susceptible to replication of IBDV (Khatri and Sharma, 2009b).

\section{MAST CELLS}

Mast cells (MCs) are present everywhere in the body especially in the tissues associated with the structure like nerves and blood vessels, and in tissues that interface the environment. MCs are responsible for the production of inflammatory substances, which indicate that MCs play a vital role in immune responses (Wang et al., 2009a; 2008). MCs recognise the viruses or dsRNA through TLR3 and produce a number of the cytokines and chemokines that leads to increase in the recruitment of the effector cells in that specific area (Abraham and St John, 2010; Moon et al., 2010). Severe histological lesions, increased MCs (at 1, 2, $3^{\text {rd }}$ DPI) and enhanced tryptase activity were observed in the thymus, spleen, glandular stomach, liver, kidney and especially in BF from infection with vvIBDV in chickens (Wang et al., 2008). Contrary to this finding, a decrease in the population of MCs were observed in the duodenum, jejunum and ileum (Figure 3) at second and third DPI with vvIBDV in specific pathogen free chickens (Wang et al., 2009b). Large quantities of tryptase in the BF, brain and other organs (which was absent in negative control) indicated that it may be involved in inflammation. Tryptase is the most abundant product of the MCs and it's quantity is directly related to the number of MCs (Wang et al., 2009a) and it can stimulate MCs secretion, causing a feedback cycle as the disease progresses (He et al., 1998). Degranulated MCs release tryptase that may then attract neighbouring MCs, leading to inflammation and lesions (Wang et al., 2009a). Treatment with ketotifen (a mast cell membrane stabiliser) in IBDV infected birds decreased MCs numbers in BF and reduced bursal damage (Wang et al., 2009a). Tissue damage and mortality can be reduced by inhibiting the MCs degranulation and mediator release in IBDV infection (Graham et al., 2015; Wang et al., 2009a). 


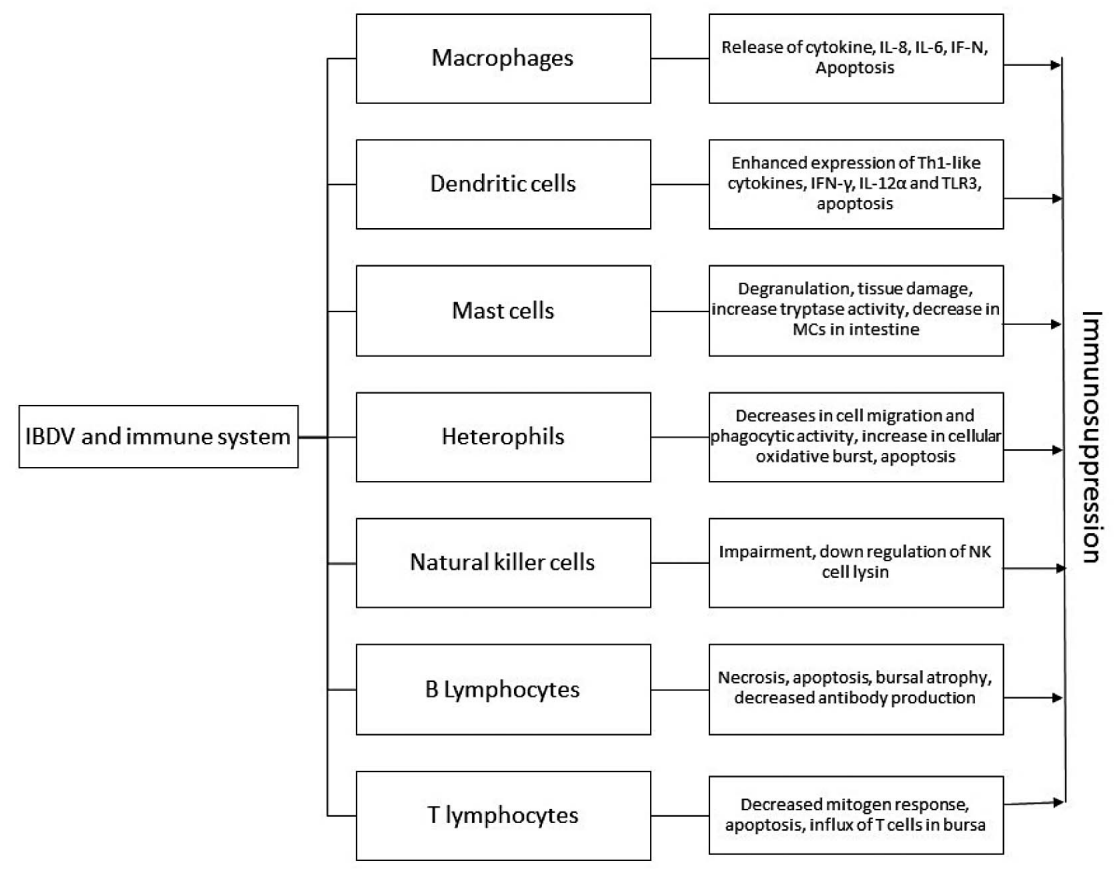

Figure 3 An outline of pathogenic and immunosuppressive aspects of IBDV (adapted from Sharma et al., 2000).

\section{HETEROPHILS}

These are the equivalent to the neutrophils in mammals (Wu and Kaiser, 2011) and belong to the polymorphonuclear leukocytes (granulocytes). Heterophils are mainly involved in the elimination of the pathogens. Granules present in the heterophils contain $\beta$-defensins (Gal-1 and Gal-2), cathepsinn, lysozyme, acid phosphatase, $\beta$ glucuronidase, and $\alpha$-glucosidase (Genovese et al., 2013), which have the antimicrobial functions. Probably activated by $\mathrm{T}$ cells, granulocytes cause release of cytokines or oxidative burst (Kogut et al., 2002). Release of cytokines and nitric oxide has been suggested as part of the IBD syndrome that resembles septic shock (Berg, 2000). The role played by the heterophils in IBDV infection is not well defined, and studies related to the functions of heterophils in IBD are lacking. The number of the heterophils entering the BF increase with acute IBDV infection (Lam, 1998). Kabell et al. (2006) have studied the effect of IBDV after pretreating the three groups with 5-fluorouracil, a placebo and 5-fluorouracil, and the results indicated that heterophil granulocytes, together with the bursal secretory DCs, contribute to the outbreak and may progress clinical symptoms. IBDV in vitro alter the functioning of heterophils, with decreases in cell migration and phagocytic activity whilst it activates cellular oxidative bursts and increases cellular adherence to the IBDV-infected chicken embryo fibroblasts of the heterophils. Electron microscopy of heterophils has shown condensed chromatin and packets of intact granules (Lam, 1997), either free or being phagocytosed by $M \Phi$, indicating that the heterophils were undergoing apoptosis. (Lam, 1998). So, it may be proposed that heterophils are one of the target cells of the immune system for IBDV. 


\section{Interaction of acquired immune responses with IBDV}

This is mainly involved in the clearance, memory and production of antibodies. IBDV infection severely affects adoptive immune responses in chickens resulting in death and secondary infections. This system has the ability to distinguish self from the foreign particles, and their destructive response should be only targeted towards foreign particles. IBDV damage the B cells, leading to lower antibody production and $\mathrm{T}$ cells, resulting in impaired virus killing ability.

\section{B- LYMPHOCYTES}

IBDV replicates in the lymphoid cells, particularly in the BF of young chickens, affecting the activity of the B cells with respect to immunoglobulin (Ig) M expression (Kong et al., 2004; Withers et al., 2006). IgM is the main antibody that is produced in the serum during the primary immune response (Maroufyan et al., 2012). During lysis, inhibition of proliferation and induction of the apoptosis causes the depletion of $\mathrm{B}$ lymphocytes (Rodriguez-Lecompte et al., 2005).B cells are the main players in the humoral immune system and their depletion leads to the immunosuppression, increasing the birds susceptibility to secondary infections (Yasmin et al., 2015) and poor vaccine titres to other diseases (Ciccone et al., 2014). IBDV do not have a significant effect on the humoral response in birds having the different genetic backgrounds (Aricibasi et al., 2010) and age (Rautenschlein et al., 2007).

Drastic decreases in IgM-bearing B cells was noted by the cytolytic effects of IBDV (Hirai et al., 1981; Kim et al., 1999), whereby infected chickens produce less antibodies for other pathogens (Kim et al., 1999). The vvIBDV (UK661) causes the depletion of the $\mathrm{Bu}-1+$, IgM+ cells from the $\mathrm{BF}$, spleen and thymus resulting in losses of mature and immature B lymphocytes. A very small number of the Bu-1+ cells were repopulated after 14 days following the infection when they were again expressing the IgM or IgG. This recovery of the B-lymphocytes was considered due to the development of two type of follicles, undifferentiated and differentiated. Plenty of the undifferentiated follicles are required for the production of antibodies against IBDV (Mahgoub et al., 2012). After the acute phase of the disease, B lymphocytes begin to appear due to the repairing of the BF, but these birds show depressed primary antibody respaces until seven weeks postinfection. The age of the bird and virus pathotype were the main factors that affected the recovery process (Schat and Skinner, 2014).

The detailed mechanism of the lysis of IBDV infected B cells is not known, but it has been assumed that IBDV affects the methylation process of the B cell genome. This highly methylated genome of B cells protect them from the mutagenic activity of activation-induced deaminase at off-target sites, as this enzyme is inefficient at deaminating 5-methylcytosine (Wijesinghe and Bhagwat, 2012). Activation-induced deaminase expressed in the $\mathrm{BF}$ is involved in antibody diversification by gene conversion in vivo, but advanced methylation may protect the reliability of the B-cell genome from over-expression of the deaminating enzyme (Ciccone et al., 2014). IBDV interruption to genomic methylation processes and an increase in global 5hydroxymethylcytosine leads to genomic instability, viral progress, cell death (Ciccone et al., 2014) and immunosuppression.

\section{T- LYMPHOCYTES}

$\mathrm{T}$ cells are important for the clearance of the infected organs after IBDV infection. IBDV vaccinated (but T cell compromised) chickens were not protected during an IBDV challenge (Rautenschlein et al., 2002). T cell compromised chickens showed fewer antibodies, higher virus titres, extensive muscular haemorrhages and suppressed 
proliferative response (Poonia and Charan, 2001). So, T cells have an important role in preventing lesions and replication of the virus in infected birds.

Significant thymocyte depletion, apoptosis (Figure 3) and decreases in the proliferation response has been observed by in ovo administration of classical virulent IBDV (Khatri and Sharma, 2009a), and reduced lymphocyte proliferation was observed in cvIBDV infected chickens by Long et al. (2011). In addition, downregulation of CD132+CD8+, upregulation of CD132+CD25+ T cells in $\mathrm{BF}$ and functional disturbance in the secretion of cytokine $\gamma \mathrm{c}$ in thymus was reported (Wang et al., 2014).

\section{CD4 AND CD8 CELLS}

CD4+ cells produce soluble $\mathrm{T}$ cell growth factors and stimulate B cell differentiation and proliferation. Perforin and granzyme-A dependant cytotoxic pathways of the cytotoxic $\mathrm{T}$ cell are mainly involved in the clearance of the IBDV from the BF, due to higher expression of these proteins in the CD4 and CD8 and BF cells (Rauf et al., 2011b). CD4 and CD8 cells populations appeared to increase in the BF, decrease in the thymus (particularly in the cortex), and show an increasing trend for CD4 and decreasing CD8, which was observed in the spleen in vvIBDV infected chickens (Carballeda et al., 2014), although results from work by Rodenberg et al. (1994) were contradictory. It is not clear whether these higher populations are due to cell migration from the tissues to the periphery or contractions of the resident cells (Rasoli et al., 2015). Bird age and genetic background differentially modulate the activity of $\mathrm{T}$ cell in IBDV infections (Rautenschlein and Haase, 2005, Tippenhauer et al., 2013). Recruitment of CD4 and CD8 T-lymphocytes enhanced damage in the BF by releasing cytokines and causing a cytotoxic effect (Wang et al., 2008) that leads to prolonged immune suppression after IBD.

It has been noted that the relative proportions of the CD4 and CD8 cells did not change in the BF after infection with cvIBDV (Rodenberg et al., 1994), although converse to these results, Williams and Davison (2005) found that CD4 and CD8 cells were obvious at 3 and 5 dpi respectively and remained at higher levels until 14 days. The $\gamma \delta \mathrm{TCR}+\mathrm{T}-$ cell population was not affected in the thymus and showed a slight increase $(\mathrm{P}<0.05)$ only at 5 dpi in BF after vvIBDV (strain UK661) infection (Williams and Davison, 2005).

\section{REGULATORY T- CELLS}

It has been well documented that CD4 CD25 regulatory $\mathrm{T}$ cells play an immunosuppressive role in many diseases (Yu et al., 2015) and the chickens CD4 CD25 cells have the similar suppressive and cytokine production properties (Shanmugasundaram and Selvaraj, 2011). Upon infection with Harbin-1 (very virulent) or Ts (moderately virulent) strains of the IBDV, CD4 CD25 cells migrated out from the thymus (observed up to $5 \mathrm{dpi}$ ) and this was more than any other CD4 cells. Infiltration of the CD4 CD25 cells along with CD4 cells was observed in the BF after IBDV infection, totalling $44.3 \% \pm 7.4 \%$ of the infiltrating CD4 cells (Yu et al., 2015). Increased numbers of the CD4 CD25 cells were detected in the peripheral blood. Viral infection is the most probable cause of the migration of the CD4 CD25 cells to the periphery, away from their origin, which affect their suppressive roles (Yu et al., 2015).

$\mathrm{T}$ cells upregulate IFN- $\gamma$ after IBDV infection (Khatri and Sharma, 2006) which inhibits the mitogenic response of the $\mathrm{T}$ cells in vitro (Sharma et al., 2000) and production of the IFN- $\gamma$ from the spleenocytes from naïve chickens. IFN- $\gamma$ reduces the production of IL-2 (Bradley et al., 1996). These activated T cells produce more IFN- $\gamma$, which stimulates $M \Phi$ to produce more cytokines. This delays the recovery process and results in $\mathrm{T}$ cell immunosuppression. The measurement of ChIFN-c after mitogen or 
antigen recall stimulation could be a good indicator of immunosuppression in chicken after IBDV infection or immunocompetence of flocks in general. IBDV infection downregulates the interferon regulatory factor (IRF) 4 and upregulates IRF1 (Guo et al., 2012), leading to the differentiation of the $\mathrm{T}$ helper cell to Th1, resulting in an inflammatory response and antibody production that may lead to immunosuppression.

\section{Immunosuppression interventions}

The ultimate goal of intervention is the prevention of economic losses due to immunosuppressive viral infections. This will be achieved mainly through biosecurity, to prevent exposure to the causes of immunosuppressive diseases, and increasing the resistance to challenge from immunosuppressive agents through carefully chosen vaccination strategies and genetic selection. Recent cloning of avian cytokine genes has shown their potential usefulness as therapeutic agents for IBD in poultry as well as vaccine adjuvants, which will become more feasible in the future. Furthermore, certain immunomodulary products have been experimentally tested and shown to reduce the severity of IBD induced lesions and consequently immunosuppression.

Currently, the disease is controlled by live attenuated or inactivated IBDV but these can revert back to virulence and may not give full protection against the vvIBDV strain. The inactivated or killed viruses are usually given to birds in the pre-laying stage to induce higher levels of antibody production for at least two weeks. By virtue of greatly advanced molecular virology and the availability of genomic information on IBDV, there are opportunities to create novel concept vaccines. DNA vaccines have great potential as an alternative capable of inducing protective immune responses against a variety of infectious diseases. Several studies have been conducted for the development of a DNA vaccine encoding the VP2 gene of IBDV, with variable protection results (Pradhan et al., 2014). However, a DNA vaccine encoding the VP2 gene alone has limited potency and results in only partial protection. Several methods have been employed to increase the efficacy of DNA vaccines including a 'DNA prime-protein boost' strategy wherein initial immunisation with plasmid DNA encoding the VP2 gene is followed by boosting with recombinant VP2 protein or killed vaccine virus, which resulted in complete protection (Gao et al., 2013). Heat shock protein (HSP) is a member of the family of molecular chaperones that assists in protein folding and processing. Fusion of antigen to HSP70 of Mycobacterium tuberculosis has been explored as a potential strategy for enhancing vaccine potency. It has been previously reported that fusion of antigen to the C-terminal domain (amino acid residues 359-610) of $M$. tuberculosis has the ability to induce antigen specific humoral, cytotoxic $\mathrm{T}$ lymphocyte and Th1 responses (Ebrahimi et al., 2012).

\section{Conclusions}

The poultry industry has economic losses due to long term IBDV mediated immunosuppression, mortality, morbidity and stunted growth. Recent developments in the understanding of immunotoxic and immunosuppressive effects of IBDV could potentially offer a way to prevent these conditions. One solution is to improve the ability of the bird to resist IBDV through genetic selection while maintaining industry standards. However, additional research is warranted to enhance understanding of immune cells and viral protein interactions to effectively design new vaccines that protect the birds from the newly emerging highly pathogenic strains, can regulate 
cytokine expressions and have the ability to activate cells of innate immune system. Future research should be focussed on developing vaccines that prevent drastic changes in cytokine expressions and activate the innate immune along with humoral immune responses to IBDV.

\section{References}

ABRAHAM, S.N. and ST JOHN, A.L. (2010) Mast cell-orchestrated immunity to pathogens. Nature Reviews Immunology 10: 440-452.

AKIRA, S. (2011) Innate immunity and adjuvants. Philosophical Transactions of the Royal Society B: Biological Sciences 366: 2748-2755.

ARICIBASI, M., JUNG, A., HELlER, E.D. and RAUTENSCHLEIN, S. (2010) Differences in genetic background influence the induction of innate and acquired immune responses in chickens depending on the virulence of the infecting IBDV strain. Veterinary Immunology and Immunopathology 135: 79-92.

BERG, T.P. (2000) Acute infectious bursal disease in poultry: A review. Avian Pathology 29: 175-194.

BRADLEY, L.M., DALTON, D.K. and CROFT, M. (1996) A direct role for ifn-gamma in regulation of th1 cell development. Journal of Immunology 157: 1350-1358.

CARBAlledA, J.M., ZOTH, S.C., GOMEZ, E., LUCERO, M.S., GRAVISACO, M.J. and BERINSTEIN, A. (2014) Immune response elicited by the oral administration of an intermediate strain of ibdv in chickens. Brazilian Journal of Microbiology 45: 1521-1525.

CHEN, Y., LU, Z., ZHANG, L., GAO, L., WANG, N., GAO, X., WANG, Y., LI, K., GAO, Y., CUI, H., GAO, H., LIU, C., ZHANG, Y., QI, X. and WANG, X. (2016) Ribosomal protein 14 interacts with viral protein vp3 and regulates the replication of infectious bursal disease virus. Virus Research 211: 73-78.

CICCONE, N.A., MWANGI, W., RUZOV, A., SMITH, L.P., BUTTER, C. and NAIR, V. (2014) A b-cell targeting virus disrupts potentially protective genomic methylation patterns in lymphoid tissue by increasing global 5-hydroxymethylcytosine levels. Veterinary Research 45: 108.

DE GEUS, E.D. and VERVELDE, L. (2013) Regulation of macrophage and dendritic cell function by pathogens and through immunomodulation in the avian mucosa. Developmental and Comparative Immunology 41: 341-351.

EBRAHIMI, S.M., DABAGHIAN, M., TEBIANIAN, M. and JAZI, M.H. (2012) In contrast to conventional inactivated influenza vaccines, $4 \mathrm{xm} 2 \mathrm{e} . \mathrm{Hsp} 70 \mathrm{c}$ fusion protein fully protected mice against lethal dose of h1, h3 and h9 influenza a isolates circulating in Iran. Virology 430: 63-72.

ELDAGHAYES, I., ROTHWELL, L., WILLIAMS, A., WITHERS, D., BALU, S., DAVISON, F. and KAISER, P. (2006) Infectious bursal disease virus: Strains that differ in virulence differentially modulate the innate immune response to infection in the chicken bursa. Viral Immunology 19: 83-91.

ESCAFFre, O., LE nOUEN, C., AMElot, M., AMBRogGiO, X., OGDEN, K.M., GUiONiE, O., TOQUIN, D., MULLER, H., ISLAM, M.R. and ETERRADOSSI, N. (2013) Both genome segments contribute to the pathogenicity of very virulent infectious bursal disease virus. Journal of Virology 87: 27672780 .

FUSSELL, L.W. (1998) Poultry industry strategies for control of immunosuppressive diseases. Poultry Science 77: 1193-1196.

GAllouX, M., Libersou, S., MOREllet, N., BOUAZIZ, S., DA COSTA, B., OULDALI, M., LEPAULT, J. and DELMAS, B. (2007) Infectious bursal disease virus, a non-enveloped virus, possesses a capsid-associated peptide that deforms and perforates biological membranes. Journal of Biological Chemistry 282: 20774-20784.

GAO, H., LI, K., GAO, L., QI, X., GAO, Y., QIN, L., WANG, Y. and WANG, X. (2013) DNA primeprotein boost vaccination enhances protective immunity against infectious bursal disease virus in chickens. Veterinary Microbiology 164: 9-17.

GENOVESE, K.J., HE, H., SWAGGERTY, C.L. and KOGUT, M.H. (2013) The avian heterophil. Developmental and Comparative Immunology 41: 334-340.

GLAS, R., FRANKSSON, L., UNE, C., ELORANTA, M. L., OHLEN, C., ORN, A. and KARRE, K. (2000) Recruitment and activation of natural killer (nk) cells in vivo determined by the target cell phenotype. An adaptive component of nk cell-mediated responses. Journal of Experimental Medicine 191: 129-138.

GRAHAM, A.C., TEMPLE, R.M. and OBAR, J.J. (2015) Mast cells and influenza a virus: Association with allergic responses and beyond. Frontiers in Immunology 6: 238.

GUO, X., WANG, L., CUI, D., RUAN, W., LIU, F. and LI, H. (2012) Differential expression of the toll-like receptor pathway and related genes of chicken bursa after experimental infection with infectious bursa disease virus. Archives of Virology 157: 2189-2199. 
HE, H., GENOVESE, K.J. and KOGUT, M.H. (2011) Modulation of chicken macrophage effector function by $\mathrm{t}(\mathrm{h}) 1 / \mathrm{t}(\mathrm{h}) 2$ cytokines. Cytokine 53: 363-369.

HE, S., GACA, M.D. and WALLS, A.F. (1998) A role for tryptase in the activation of human mast cells: Modulation of histamine release by tryptase and inhibitors of tryptase. Journal of Pharmacology and Experimental Therapeutics 286: 289-297.

HIRAI, K., FUNAKOSHI, T., NAKAI, T. and SHIMAKURA, S. (1981) Sequential changes in the number of surface immunoglobulin-bearing b lymphocytes in infectious bursal disease virus-infected chickens. Avian Diseases 25: 484-496.

INOUE, M., YAMAMOTO, H., MATUO, K. and HIHARA, H. (1992) Susceptibility of chicken monocytic cell lines to infectious bursal disease virus. Journal of Veterinary Medical Science 54: 575-577.

JUUL-MADSEN, H.R., VIERTLBÖECK, B., HÄRTLE, S., SMITH, A.L. and GÖBEL, T.W. (2014) Innate immune responses, in: SCHAT, K.A., KASPERS, B. \& KAISER, P. (Eds) Avian Immunology, pp. 121-147 (Boston, Academic Press).

KABELL, S., IGYARTO, B.Z., MAGYAR, A., HAJDU, Z., BIRO, E., BISGAARD, M. and OLAH, I. (2006) Impact of heterophil granulocyte depletion caused by 5 -fluorouracil on infectious bursal disease virus infection in specific pathogen free chickens. Avian Pathology 35: 341-348.

KHATRI, M., PALMQUIST, J.M., CHA, R.M. and SHARMA, J.M. (2005) Infection and activation of bursal macrophages by virulent infectious bursal disease virus. Virus Research 113: 44-50.

KHATRI, M. and SHARMA, J.M. (2006) Infectious bursal disease virus infection induces macrophage activation via p38 mapk and nf-kappab pathways. Virus Research 118: 70-77.

KHATRI, M. and SHARMA, J.M. (2008) Ifn-gamma upregulation and protection by macrophage-adapted infectious bursal disease virus. Vaccine 26: 4740-4746.

KHATRI, M. and SHARMA, J.M. (2009a) Response of embryonic chicken lymphoid cells to infectious bursal disease virus. Veterinary Immunology and Immunopathology 127: 316-324.

KHATRI, M. and SHARMA, J.M. (2009b) Susceptibility of chicken mesenchymal stem cells to infectious bursal disease virus. Journal of Virological Methods 160: 197-199.

KIM, I.J., GAGIC, M. and SHARMA, J.M. (1999) Recovery of antibody-producing ability and lymphocyte repopulation of bursal follicles in chickens exposed to infectious bursal disease virus. Avian Diseases 43: 401-413.

KIM, I.J., KARACA, K., PERTILE, T.L., ERICKSON, S.A. and SHARMA, J.M. (1998) Enhanced expression of cytokine genes in spleen macrophages during acute infection with infectious bursal disease virus in chickens. Veterinary Immunology and Immunopathology 61: 331-341.

KOGUT, M., ROTHWELL, L. and KAISER, P. (2002) Differential effects of age on chicken heterophil functional activation by recombinant chicken interleukin-2. Developmental and Comparative Immunology 26: $817-830$

KONG, L.L., OMAR, A.R., HAIR-BEJO, M., AINI, I. and SEOW, H.F. (2004) Comparative analysis of viral rna and apoptotic cells in bursae following infection with infectious bursal disease virus. Comparative Immunology Microbiology and Infectious Diseases 27: 433-443.

KUMAR, P.A., DAS, S.K. and RAO, J.R. (1998) Effect of immunostimulation on cytotoxic activity of intestinal intraepithelial lymphocytes of chickens in infectious bursal disease and eimeria tenella infections. Acta Veterinaria Hungarica 46: 1-11.

LAM, K.M. (1997) Morphological evidence of apoptosis in chickens infected with infectious bursal disease virus. Journal of Comparative Pathology 116: 367-377.

LAM, K.M. (1998) Alteration of chicken heterophil and macrophage functions by the infectious bursal disease virus. Microbial Pathogenesis 25: 147-155.

LEE, C.C., KIM, B.S., WU, C.C. and LIN, T.L. (2015a) Bursal transcriptome of chickens protected by DNA vaccination versus those challenged with infectious bursal disease virus. Archives of Virology 160: 69-80.

LEE, C.C., WU, C.C. and LIN, T.L. (2014) Chicken melanoma differentiation-associated gene 5 (mda5) recognizes infectious bursal disease virus infection and triggers mda5-related innate immunity. Archives of Virology 159: 1671-1686.

LEE, C.C., WU, C.C. and LIN, T.L. (2015b) Role of chicken melanoma differentiation-associated gene 5 in induction and activation of innate and adaptive immune responses to infectious bursal disease virus in cultured macrophages. Archives of Virology 160: 3021-3035.

LEVITZ, S.M. and GOLENBOCK, D.T. (2012) Beyond empiricism: Informing vaccine development through innate immunity research. Cell 148: 1284-1292.

LI, K., GAO, H., GAO, L., QI, X., GAO, Y., QIN, L., WANG, Y. and WANG, X. (2013a) Adjuvant effects of interleukin-18 in DNA vaccination against infectious bursal disease virus in chickens. Vaccine 31: 17991805 .

LI, Y.P., HANDBERG, K.J., JUUL-MADSEN, H.R., ZHANG, M.F. and JORGENSEN, P.H. (2007) Transcriptional profiles of chicken embryo cell cultures following infection with infectious bursal disease virus. Archives of Virology 152: 463-478. 
LI, Z., WANG, Y., LI, X., LI, X., CAO, H. and ZHENG, S.J. (2013b) Critical roles of glucocorticoidinduced leucine zipper in infectious bursal disease virus (ibdv)-induced suppression of type i interferon expression and enhancement of ibdv growth in host cells via interaction with vp4. Journal of Virology 87: 1221-1231.

LIANG, J., YIN, Y., QIN, T. and YANG, Q. (2015) Chicken bone marrow-derived dendritic cells maturation in response to infectious bursal disease virus. Veterinary Immunology and Immunopathology 164: 51-55.

LIU, H., ZHANG, M., HAN, H., YUAN, J. and LI, Z. (2010) Comparison of the expression of cytokine genes in the bursal tissues of the chickens following challenge with infectious bursal disease viruses of varying virulence. Virology Journal 7: 364.

LIU, Y.J. (2001) Dendritic cell subsets and lineages, and their functions in innate and adaptive immunity. Cell 106: $259-262$

LONG, F.Y., GUO, Y.M., WANG, Z., LIU, D., ZHANG, B.K. and YANG, X. (2011) Conjugated linoleic acids alleviate infectious bursal disease virus-induced immunosuppression in broiler chickens. Poultry Science 90: 1926-1933.

MAHGOUB, H.A., BAILEY, M. and KAISER, P. (2012) An overview of infectious bursal disease. Archives of Virology 157: 2047-2057.

MANDAL, A. and VISWANATHAN, C. (2015) Natural killer cells: In health and disease. Hematology/ Oncology and Stem Cell Therapy 8: 47-55.

MAROUFYAN, E., KASIM, A., EBRAHIMI, M., LOH, T.C., BEJO, M.H., ZERIHUN, H., HOSSENI, F., GOH, Y.M. and FARJAM, A.S. (2012) Omega-3 polyunsaturated fatty acids enrichment alters performance and immune response in infectious bursal disease challenged broilers. Lipids in Health and Disease 11: 15.

MOGENSEN, T.H. (2009) Pathogen recognition and inflammatory signaling in innate immune defenses. Clinical Microbiology Reviews 22: 240-273.

MOON, T.C., ST LAURENT, C.D., MORRIS, K.E., MARCET, C., YOSHIMURA, T., SEKAR, Y. and BEFUS, A.D. (2010) Advances in mast cell biology: New understanding of heterogeneity and function. Mucosal Immunology 3: 111-128.

MÜLLER, H., SCHOLTISSEK, C. and BECHT, H. (1979) The genome of infectious bursal disease virus consists of two segments of double-stranded rna. Journal of Virology 31: 584-589.

NDASHE, K., SIMULUNDU, E., HANG'OMBE, B.M., MOONGA, L., OGAWA, H., TAKADA, A. and MWEENE, A.S. (2016) Molecular characterisation of infectious bursal disease viruses detected in vaccinated commercial broiler flocks in Lusaka, Zambia. Archives of Virology 161: 513-519.

OUYANG, W., WANG, Y.S., DU, X.N., LIU, H.J. and ZHANG, H.B. (2015) Gga-mir-9* inhibits ifn production in antiviral innate immunity by targeting interferon regulatory factor 2 to promote ibdv replication. Veterinary Microbiology 178: 41-49.

PALMQUIST, J.M., KHATRI, M., CHA, R.M., GODDEERIS, B.M., WALCHECK, B. and SHARMA, J. M. (2006) In vivo activation of chicken macrophages by infectious bursal disease virus. Viral Immunology 19: 305-315.

POONIA, B. and CHARAN, S. (2001) T-cell suppression by cyclosporin-a enhances infectious bursal disease virus infection in experimentally infected chickens. Avian Pathology 30: 311-319.

PRADHAN, S.N., PRINCE, P.R., MADHUMATHI, J., ARUNKUMAR, C., ROY, P., NARAYANAN, R. B. and ANTONY, U. (2014) DNA vaccination with vp2 gene fragment confers protection against infectious bursal disease virus in chickens. Veterinary Microbiology 171: 13-22.

PRANDINI, F., SIMON, B., JUNG, A., POPPEL, M., LEMIERE, S. and RAUTENSCHLEIN, S. (2016) Comparison of infectious bursal disease live vaccines and a hvt-ibd vector vaccine and their effects on the immune system of commercial layer pullets. Avian Pathology 45: 114-125.

QI, X., CHEN, Y., REN, X., ZHANG, L., GAO, L., WANG, N., QIN, L., WANG, Y., GAO, Y. and WANG, X. (2014) A reassortment vaccine candidate as the improved formulation to induce protection against very virulent infectious bursal disease virus. Vaccine 32: 1436-1443.

RASOLI, M., YEAP, S.K., TAN, S.W., ROOHANI, K., KRISTEEN-TEO, Y.W., ALITHEEN, N.B., RAHAMAN, Y.A., AINI, I., BEJO, M.H., KAISER, P. and OMAR, A.R. (2015) Differential modulation of immune response and cytokine profiles in the bursae and spleen of chickens infected with very virulent infectious bursal disease virus. BMC Veterinary Research 11: 75.

RAUF, A., KHATRI, M., MURGIA, M.V., JUNG, K. and SAIF, Y.M. (2011a) Differential modulation of cytokine, chemokine and toll like receptor expression in chickens infected with classical and variant infectious bursal disease virus. BMC Veterinary Research 42: 85 .

RAUF, A., KHATRI, M., MURGIA, M.V. and SAIF, Y.M. (2011b) Expression of perforin-granzyme pathway genes in the bursa of infectious bursal disease virus-infected chickens. Developmental and Comparative Immunology 35: 620-627.

RAUTENSCHLEIN, S. and HAASE, C. (2005) Differences in the immunopathogenesis of infectious bursal disease virus (ibdv) following in ovo and post-hatch vaccination of chickens. Veterinary Immunology and Immunopathology 106: 139-150. 
RAUTENSCHLEIN, S., VON SAMSON-HIMMELSTJERNA, G. and HAASE, C. (2007) A comparison of immune responses to infection with virulent infectious bursal disease virus (ibdv) between specific-pathogenfree chickens infected at 12 and 28 days of age. Veterinary Immunology and Immunopathology 115: 251-260.

RAUTENSCHLEIN, S., YEH, H.Y. and SHARMA, J.M. (2002) The role of t cells in protection by an inactivated infectious bursal disease virus vaccine. Veterinary Immunology and Immunopathology 89: 159167.

RAUW, F., LAMBRECHT, B. and VAN DEN BERG, T. (2007) Pivotal role of chifngamma in the pathogenesis and immunosuppression of infectious bursal disease. Avian Pathology 36: 367-374.

RODENBERG, J., SHARMA, J.M., BELZER, S.W., NORDGREN, R.M. and NAQI, S. (1994) Flow cytometric analysis of $\mathrm{b}$ cell and $\mathrm{t}$ cell subpopulations in specific-pathogen-free chickens infected with infectious bursal disease virus. Avian Diseases 38: 16-21.

RODRIGUEZ-LECOMPTE, J.C., NINO-FONG, R., LOPEZ, A., FREDERICK MARKHAM, R.J. and KIBENGE, F.S. (2005) Infectious bursal disease virus (ibdv) induces apoptosis in chicken b cells. Comparative Immunology Microbiology and Infectious Diseases 28: 321-337.

SCANES, C.G. (2015) Blood, in: SCANES, C.G. (Ed) Sturkie's Avian Physiology, pp. 167-191 (San Diego, Academic Press).

SCHAT, K.A. and SKINNER, M.A. (2014) Avian immunosuppressive diseases and immunoevasion, in: SCHAT, K.A., KASPERS, B. \& KAISER, P. (Eds) Avian Immunology, pp. 275-297 (Boston, Academic Press).

SHANMUGASUNDARAM, R. and SELVARAJ, R.K. (2011) Regulatory t cell properties of chicken cd4 + cd25+ cells. Journal of Immunology 186: 1997-2002.

SHARMA, J.M., KIM, I.J., RAUTENSCHLEIN, S. and YEH, H.Y. (2000) Infectious bursal disease virus of chickens: Pathogenesis and immunosuppression. Developmental and Comparative Immunology 24: 223-235.

SHARMA, J.M. and LEE, L.F. (1983) Effect of infectious bursal disease on natural killer cell activity and mitogenic response of chicken lymphoid cells: Role of adherent cells in cellular immune suppression. Infection and Immunity 42: 747-754.

TIPPENHAUER, M., HELLER, D.E., WEIGEND, S. and RAUTENSCHLEIN, S. (2013) The host genotype influences infectious bursal disease virus pathogenesis in chickens by modulation of $\mathrm{t}$ cells responses and cytokine gene expression. Developmental and Comparative Immunology 40: 1-10.

VAN DEN BERG, T.P., ETERRADOSSI, N., TOQUIN, D. and MEULEMANS, G. (2000) Infectious bursal disease (gumboro disease). Revue Scientifique et Technique 19: 509-543.

WANG, D., LIU, Y., SHE, R., XU, J., LIU, L., XIONG, J., YANG, Y., SUN, Q. and PENG, K. (2009a) Reduced mucosal injury of spf chickens by mast cell stabilisation after infection with very virulent infectious bursal disease virus. Veterinary Immunology and Immunopathology 131: 229-237.

WANG, D., XIONG, J., SHE, R., LIU, L., ZHANG, Y., LUO, D., LI, W., HU, Y., WANG, Y., ZHANG, Q. and SUN, Q. (2008) Mast cell mediated inflammatory response in chickens after infection with very virulent infectious bursal disease virus. Veterinary Immunology and Immunopathology 124: 19-28.

WANG, D., ZHOU, X., SHE, R., XIONG, J., SUN, Q., PENG, K., LIU, L. and LIU, Y. (2009b) Impaired intestinal mucosal immunity in specific-pathogen-free chickens after infection with very virulent infectious bursal disease virus. Poultry Science 88: 1623-1628.

WANG, S., TENG, Q., JIA, L., SUN, X., WU, Y. and ZHOU, J. (2014) Infectious bursal disease virus influences the transcription of chicken gammac and gammac family cytokines during infection. PloS One 9: e84503.

WIJESINGHE, P. and BHAGWAT, A.S. (2012) Efficient deamination of 5-methylcytosines in DNA by human apobec3a, but not by aid or apobec3g. Nucleic Acids Research 40: 9206-9217.

WILLIAMS, A.E. and DAVISON, T.F. (2005) Enhanced immunopathology induced by very virulent infectious bursal disease virus. Avian Pathology 34: 4-14.

WITHERS, D.R., DAVISON, T.F. and YOUNG, J.R. (2006) Diversified bursal medullary b cells survive and expand independently after depletion following neonatal infectious bursal disease virus infection. Immunology 117: 558-565.

WONG, R.T., HON, C.C., ZENG, F. and LEUNG, F.C. (2007) Screening of differentially expressed transcripts in infectious bursal disease virus-induced apoptotic chicken embryonic fibroblasts by using cdna microarrays. Journal of General Virology 88: 1785-1796.

WU, Z. and KAISER, P. (2011) Antigen presenting cells in a non-mammalian model system, the chicken. Immunobiology 216: 1177-1183.

YASMIN, A.R., YEAP, S.K., TAN, S.W., HAIR-BEJO, M., FAKURAZI, S., KAISER, P. and OMAR, A. R. (2015) In vitro characterisation of chicken bone marrow-derived dendritic cells following infection with very virulent infectious bursal disease virus. Avian Pathology 44: 452-462.

YE, C., JIA, L., SUN, Y., HU, B., WANG, L., LU, X. and ZHOU, J. (2014) Inhibition of antiviral innate immunity by birnavirus vp3 protein via blockage of viral double-stranded rna binding to the host cytoplasmic rna detector mda5. Journal of Virology 88: 11154-11165. 
Immune interactions of infectious bursal disease virus: Z.U. Rehman et al.

YU, X., RUI, L., SHAO, Q., LIU, H., LU, Y., ZHANG, Y. and LI, Z. (2015) Changes of cd4 + cd $25+$ cells ratio in immune organs from chickens challenged with infectious bursal disease virus strains with varying virulences. Viruses 7: 1357-1372.

ZHAI, L., WANG, Y., YU, J. and HU, S. (2014) Enhanced immune responses of chickens to oral vaccination against infectious bursal disease by ginseng stem-leaf saponins. Poultry Science 93: 2473-2481. 